\title{
ARTIKELEN
}

THEMA-ARTIKEL

\section{Onafhankelijk onderzoek in positie, oordeelsvorming en beeldvorming}

\section{Institutionele en professionele dimensies van 'speaking truth to power"*}

Peter van der Knaap, Meike Bokhorst \& Yvonne Kleistra

\begin{abstract}
Twijfel aan de onafhankelijkheid van onderzoek leidt regelmatig tot hoogoplopende discussies. Dat geldt met name als er dingen niet goed zijn gegaan. Dit themanummer verkent de vraag hoe onderzoeksorganisaties en onderzoekers zich kunnen verweren tegen oneigenlijke beïnvloeding: het bewust en actief nastreven van te positieve uitkomsten van onderzoek door opdrachtgevers of overheden. Dankzij de bijdragen van de auteurs uit de werelden van de Onderzoeksraad voor Veiligheid, het Planbureau voor de Leefomgeving, het Rathenau Instituut, de Nationale Ombudsman en de wereld van het biomedisch onderzoek worden in dit artikel een aantal dimensies geschetst hoe op een systematische en verstandige manier werken aan goed, onafhankelijk onderzoek kan worden vormgegeven. Onafhankelijkheid manifesteert zich in positie, oordeelsvorming en beeldvorming. Institutionele, 'harde' waarborgen zoals formele positie en financiën vormen daarbij de basis voor professionele rollen en andere 'zachte' verantwoordelijkheden die onafhankelijkheid in de politieke arena kunnen waarmaken.
\end{abstract}

\section{Een brandende kwestie}

Razende vuurstormen trekken over strand en boulevard. Een regen van vonken en roet teistert Scheveningen. Hoe heeft het zo mis kunnen gaan met de vreugdevuren op het strand? Waarom mocht dit? De burgemeester kondigt een minutieuze evaluatie aan, onder regie van de directeur veiligheid van de gemeente Den Haag. Raadsleden pleiten vurig voor onafhankelijk onderzoek. En op zich is dat niet vreemd. Het 'enkele feit dat instituties zelf onderzoek uitvaardigen, stemt vaak al wantrouwig', stelde Nationale Ombudsman Reinier van Zutphen hierover nog onlangs (Onderzoeksraad, 2018, p. 20). Geen wonder dus, dat vaak gekozen

* $\quad$ Dr. P. van der Knaap is directeur-bestuurder van SWOV, voorzitter van Vide en redactielid van Bestuurskunde. Dr. A.M. Bokhorst is onderzoeker bij de Wetenschappelijke Raad voor het Regeringsbeleid en bij de Universiteit Utrecht. Dr. Y. Kleistra is universitair docent aan de Universiteit Leiden en redactielid van Bestuurskunde. 
wordt voor een onafhankelijke commissie die rampen of bijna-rampen moet evalueren.

U weet hoe het afloopt. Negen maanden later ligt er een kritisch rapport van de Onderzoeksraad voor Veiligheid. De burgemeester stapt op.

Het meest gehoorde argument in de politieke arena voor onafhankelijk onderzoek is dat 'de slager zijn eigen vlees niet mag keuren'. Ook in Den Haag klonk deze klassieker. Een goede tweede plaats is weggelegd voor 'Wij van WC-eend...'. Op de derde plaats staat het klassieke 'wiens brood men eet diens woord men spreekt'. Oftewel: je kiest partij voor degene van wie je afhankelijk bent. Het resultaat is in alle gevallen dat informatie niet vertrouwd wordt. Of, in termen van de politieke arena: de waarheid komt niet boven water waardoor verantwoordelijkheden worden ontlopen.

Een sterke onafhankelijke positie van onderzoeksorganisaties en -commissies en professionele weerbaarheid van onderzoekers moeten deze risico's ondervangen. Maar is het nu wel zo dat onafhankelijkheid altijd een panacee is? Sterker nog: bestáát echte onafhankelijkheid eigenlijk wel? Is het altijd wenselijk? Je kunt er genuanceerd naar kijken en dat is precies wat dit themanummer beoogt te doen. Vertrekpunt daarbij is de opdracht die Wildavsky meegaf aan onderzoekers en evaluatoren: 'Speaking truth to power' (1979).

Vooropgesteld: er zijn weinig onderwerpen die zo snel tot hoogoplopende discussies kunnen leiden als twijfel aan de onafhankelijkheid van onderzoek. Denk aan de discussies over de stikstofberekeningen van het RIVM, de energiecijfers van het PBL of de drugsonderzoeken van het Wetenschappelijk Onderzoek- en Documentatiecentrum (WODC). Maar ook aan spraakmakende publicaties als die van de KNAW (2005), de WRR (2013), NWO (2018) of aan pleidooien voor een Kaderwet Onafhankelijk Onderzoek (SMV, 2018). De bijdrage van Wim Derksen, elders in dit nummer, kan overigens ook in dat licht worden gelezen. Het betreft stuk voor stuk zaken die bij een vermeend (!) gebrek aan onafhankelijkheid snel controversieel kunnen worden. Dat is - zoals Van Zutphen aangeeft - van meet af aan het geval bij misstanden of ongevallen: wie die niet onafhankelijk laat onderzoeken, is stante pede verdacht. En vaak al bij voorbaat veroordeeld. Dat geldt zowel voor 'de politiek' als voor 'de media'.

Vreemd is dit niet: grote (overheids)organisaties beschikken immers over de macht en de middelen om kennis over beleidsvraagstukken en hun eigen functioneren te beïnvloeden. Die beïnvloeding is oneigenlijk als daarmee bewust en actief een te positief beeld wordt nagestreefd. Voor Wildavsky schuilt juist daarin het belang van onafhankelijk onderzoek: 'The ability of organizations to please themselves must ultimately (at least in a democratic society) give way to appraisal by outsiders' (1979, p. 233).

Tegelijkertijd heeft Wildavsky wel degelijk oog voor legitieme belangen en zorgen van beleid en bestuur. Beleidsonderzoek zou volgens hem de belangen van het politieke bestuur moeten koppelen aan de uitkomsten van beleid. Voor hem is dat 
zelfs bepalend voor de wijze waarop onderzoek wordt benut (1979, p. 231). Ook veel onderzoekers zijn zich ervan bewust dat een te afstandelijke opstelling nadelen heeft, zowel voor de kwaliteit van het onderzoek zelf als voor de kans dat er iets met de onderzoeksresultaten wordt gedaan. De opkomst van responsief evaluatieonderzoek is wat dat betreft veelzeggend: juist door expliciet rekening te houden met de opvattingen en appreciaties van belanghebbenden, waaronder beleidsmakers en bestuurders, wordt doelbewust gewerkt aan het verkleinen van de afstand tussen onderzoekers en onderzochten. Daarnaast geldt heel praktisch: iemand moet het onderzoek bekostigen, ook als dat door universiteiten wordt gedaan.

De vraag is dan ook: hoe kun je op een systematische en verstandige manier werken aan goed, onafhankelijk onderzoek?

\section{De bijdragen van dit themanummer}

Deze en andere vragen liggen ten grondslag aan dit themanummer van Bestuurskunde. De bijdragen uit de werelden van de Onderzoeksraad voor Veiligheid, het Planbureau voor de Leefomgeving, het Rathenau Instituut, de Nationale Ombudsman en de wereld van het biomedisch onderzoek bieden verschillende perspectieven en handvatten.

De auteurs onderschrijven zonder uitzondering - en zonder betaling of andersoortige pressie door de themaredactie van dit nummer - het belang van onafhankelijk onderzoek. Opdrachtgevers mogen meepraten over wat er wordt onderzocht. Maar onderzoekers moeten kunnen bepalen hoe zij hun onderzoeken verrichten en dienen vrij te zijn van invloed op de manier waarop zij over onderzoeksresultaten rapporteren. Brede consensus bestaat er over de bijdrage van onafhankelijk onderzoek voor het vertrouwen dat mensen kunnen hebben in beleid en politiek en, breder, voor de kwaliteit van interventies die erop gericht zijn ons leven beter te maken. Ook zijn de auteurs het erover eens dat formele waarborgen niet voldoende zijn: instituten en onderzoekers hebben ook een eigen verantwoordelijkheid bij het waarmaken van professionele onafhankelijkheid.

Marjolein van Asselt, Marjan Slob, Marjolein Baart, Dirk Ipenburg en Mirjam van het Loo gaan in 'Onafhankelijk onderzoek in het publiek belang - Aanknopingspunten voor de praktijk' in op de inzichten die de Onderzoeksraad voor Veiligheid heeft verzameld over de vraag wat onafhankelijkheid in theorie en in de praktijk behelst. Onafhankelijk definiëren zij als onderzoek zonder inmenging van de politiek en politieke gezagsdragers: belanghebbenden mogen geen grip hebben op de aanpak en uitkomst van onderzoek. Uit de vele gesprekken die de auteurs hebben gevoerd met onderzoekers, opdrachtgevers en ontvangers van onderzoek, schetsen zij drie hoekstenen voor onafhankelijk onderzoek: positie, oordeelsvorming en beeldvorming. Daarnaast schetst het artikel een aantal voorwaarden om onafhankelijkheid waar te kunnen maken: (1) onderzoekscommissies en -instanties moeten zelf hun onderzoeksvraag kunnen formuleren, (2) zij dienen als enige 
zeggenschap te hebben over bevindingen en conclusies, (3) zij moeten zelf hun onderzoeksteam kunnen samenstellen en (4) de manier van onderzoek mag alleen door hen bepaald worden.

Femke Verwest, Eva Kunseler, Paul Diederen en Patricia Faasse richten zich op de vraag wat onderzoeksorganisaties nodig hebben om onafhankelijkheid te kunnen borgen. Zij gaan in op de harde formele waarborgen en zachte praktijken van het werken aan onafhankelijk onderzoek. Harde maatregelen omvatten de formele juridische positie ten opzichte van de overheid, wettelijke bepalingen en geformaliseerde institutionele arrangementen (zoals gedragscodes, protocollen en adviesraden). Zachte borging komt volgens de auteurs tot uitdrukking in hoe management en onderzoekers rollen en verantwoordelijkheden als professionals waarmaken en elkaar daarop aanspreken. Aangezien ongewenste beïnvloeding verschillende gedaanten kan aannemen, is 'weerbaarheid' bij het werk van onderzoekers per definitie maatwerk. De auteurs schetsen de stappen die het Planbureau voor de Leefomgeving heeft ondernomen om op projectniveau de professionele omgang met onafhankelijkheid te bevorderen. Aan de hand van praktijkvoorbeelden wordt duidelijk gemaakt dat het borgen van onafhankelijkheid feitelijk een continue opdracht is voor iedere onderzoeksorganisatie en aanzienlijke inspanningen en investeringen van management en onderzoekers vergt. De professionele attitude van de onderzoeker blijkt uiteindelijk bepalend.

Dat laatste thema keert ook terug in het interview dat Yvonne Kleistra en Peter van der Knaap hadden met Reinier van Zutphen over het belang van onafhankelijk toezicht en onderzoek voor de Nationale Ombudsman. Van Zutphen benadrukt het belang van juridische voorwaarden en van een interne cultuur en structuur die onderzoekers sterk in hun schoenen doen staan. De harde en zachte kant van onafhankelijkheid vormen samen een medaille: er moet ruimte zijn voor onderzoekers om zelf onafhankelijkheid te ervaren, maar regels en wetten zijn onmisbaar om, als het er echt op aankomt, ook waar te kunnen maken dat je als instituut onafhankelijk en niet beïnvloedbaar bent.

Frits Roosendaal gaat in een openhartige bijdrage in op de prikkels, druk en sturing in biomedisch onderzoek. Zijn conclusie is dat tussen academische onderzoekers van geneesmiddelen en de farmaceutische industrie alle ingrediënten voor ongewenste belangenverstrengeling aanwezig zijn. De financiële belangen zijn over en weer groot, de arts is monopolist bij het doen van onderzoek en het voorschrijven van medicijnen, en farmaceuten, academische ziekenhuizen en specialisten zijn gevangen in een spiraal van meer projecten, meer gezag, meer invloed en meer geld. Zijn conclusie is duidelijk: onderzoek naar de werkzaamheid van geneesmiddelen is vrijwel nooit als onafhankelijk te zien. Roosendaal toont aan dat onderzoek dat uit algemene middelen wordt bekostigd andere uitkomsten laat zien dan onderzoek dat door de farmaceutische industrie wordt betaald. Hij pleit voor een versterking van bestaande instrumenten - medisch-ethische commissies, transparantieregister, verklaringen van belangen - maar vooral voor een fundamenteel nieuwe manier van bekostiging. 
Meike Bokhorst stelt - als onderzoeker van de onderzoekscommissie die de relatie tussen beleidsdepartement en het Wetenschappelijk Onderzoek- en Documentatiecentrum (WODC) heeft onderzocht - ten slotte de vraag wat we kunnen leren van 'de WODC-affaire'. In het rapport stelt de commissie dat er een terugkerend patroon is waarin sommige medewerkers van het ministerie van JenV proberen om WODC-onderzoek te beïnvloeden. Hierbij is sprake van een machtscultuur, waarin onderzoekers in 'een spel van duwen en terugduwen' hun inhoudelijke onafhankelijkheid steeds opnieuw moeten bevechten. Vooral bij politiek gevoelige onderwerpen staan onderzoekers bloot aan stevige beleidsdruk en is er sprake van (pogingen tot) oneigenlijke beïnvloeding. De auteur concludeert in navolging van Verwest c.s. dat het versterken van harde en zachte onafhankelijkheidswaarborgen kan helpen om toekomstige incidenten tegen te gaan.

\section{Instituties en professionals: koppelingen tussen harde en zachte waarborgen}

Wat zijn, alles overziende, de lessen van dit themanummer over het belang van onafhankelijk onderzoek in de politieke arena?

De belangrijkste is dat je er als onderzoeksinstelling gericht aan kunt werken dat het werk van onderzoekers niet oneigenlijk wordt beïnvloed door politieke en bestuurlijke machthebbers. De drie facetten van onafhankelijk onderzoek zoals de Onderzoeksraad voor Veiligheid die herkent - positie, oordeelsvorming en beeldvorming - laten zich daarbij goed combineren met de door de auteurs beschreven 'harde' voorwaarden en 'zachte' maatregelen. Harde maatregelen die de formele positie, wettelijke bevoegdheden en protocollen vestigen, vormen daarbij de institutionele basis voor de aanvullende zachte borging, die tot uitdrukking komt in hoe management en onderzoekers rollen en verantwoordelijkheden als professionals waarmaken.

Dit leidt tot zes dimensies voor het gericht werken aan onafhankelijk onderzoek, waarvan er - althans in een kennisdemocratie zoals de onze - slechts één louter theoretisch bestaat (hoewel dat in de nabije toekomst al kan veranderen). Met de dimensies willen wij nadrukkelijk niet pretenderen dat daarmee alles gezegd is ons motief is het bieden van een overzicht:

Dimensie 1: positie omgeven met harde waarborgen - het belang van rechtsvorm, regels en financiën

Een duidelijke en stevige positie van onderzoekers en instituten kan worden gezien als een cruciale voorwaarde voor hoogwaardig onafhankelijk onderzoek. Tegelijkertijd verschilt de juridische borging van de onafhankelijkheid van onderzoek tussen instellingen en ook commissies sterk: van een grondwettelijke borging bij de Hoge Colleges van Staat tot aan convenanten zoals - tot voor kort - bij het WODC en KiM. Het kunnen beschikken over voldoende financiële middelen vormt een belangrijke voorwaarde voor onafhankelijk onderzoek. Het bestaan van een rechtstreeks aan individuele onderzoeken gekoppelde geldstroom tussen opdrachtgever en opdrachtnemer is onwenselijk, vooral als de uitkomsten van 
onderzoek rechtstreeks gevolgen hebben voor de (deel)belangen van die opdrachtgevers.

Inhoudelijk is een gegarandeerde vrije keuze van onderwerpen en vraagstelling en, daaraan gekoppeld, van methoden en rapportagevorm van cruciaal belang. Oneigenlijke beïnvloeding begint soms al bij de toespitsing van de onderwerpkeuze, de formulering van de vraagstelling en de keuze voor bepaalde methoden en technieken. Positief is dat een aantal onderzoeksorganisaties naar aanleiding van discussies over onafhankelijkheid hun missie en positie hebben geëxpliciteerd, bijvoorbeeld op hun website of in hun rapporten. Wetenschappelijke waarborgen en de principes van bijvoorbeeld VSNU en KNAW, maar ook die van de Vereniging voor Beleidsonderzoek of de European Evaluation Society (EES) zijn ook nuttig voor het expliciet maken van de institutionele positie. ${ }^{1}$ Hetzelfde geldt voor normen uit de Regeling Periodiek Evaluatieonderzoek en documenten als de Aanwijzingen van de Minister-President voor de rijksinspecties.

\section{Dimensie 2: positie versterkt met zachte maatregelen - het belang van relaties en responsiviteit}

Naast de formele positie, voldoende financiële middelen en vrije inhoudelijke keuze bieden het goed onderhouden van relaties en het organiseren van voldoende responsiviteit ook een aangrijpingspunt om te sturen op onafhankelijkheid in onderzoek. Het gaat daarbij vooral om het vinden van de balans tussen 'de ivoren toren' die wars is van elke vorm van beïnvloeding door maatschappelijke of politieke werkelijkheden en 'de windvaan zonder ruggengraat' die tegen geen enkele beïnvloedingspoging bestand is. Door het voeren van een actief 'relatiemanagement' met de belangrijkste belanghebbende actoren in het veld kunnen de missie en positie van een onderzoeksinstituut of -commissie duidelijk worden gemaakt én kan nabijheid worden geborgd. Door het instellen van begeleidingsgroepen en leescommissies kan op een transparante wijze de verbinding worden gemaakt tussen onderzoeker en onderzochte.

\section{Dimensie 3: oordeelsvorming omgeven met harde waarborgen - het belang van procedures en kwaliteitszorg}

De onafhankelijkheid in oordeelsvorming is gebaat bij duidelijke regels over verantwoordelijkheden en procedures. Een voorbeeld is het organiseren van hoor en wederhoor, maar ook een formeel systeem van kwaliteitszorg kan bijdragen aan de robuustheid van de oordeelsvorming. Tegelijkertijd, zo leert de casus van het biomedisch onderzoek, is transparantie in methoden en procedures niet altijd voldoende: wie kwaad wil, kan kwaad verbergen.

1 Zie bijvoorbeeld www.knaw.nl/shared/resources/actueel/bestanden/wetenschappelijke_onafhan kelijkheid.pdf. 
Dimensie 4: oordeelsvorming versterkt met zachte maatregelen - het belang van onderzoekersattitude, 'bevleugelend' leiderschap en motivatie vanuit het publieke belang

Uit elke bijdrage blijkt het belang van gemotiveerde onderzoekers met een onafhankelijke attitude. Voor werkelijk onafhankelijke oordeelsvorming is het zaak dat onderzoekers de bereidheid om eigen werk, waarden en (voor)oordelen ter discussie te stellen koppelen aan de bereidheid om oneigenlijke aanvallen op hun onderzoek en de resultaten ervan fel te bestrijden. Het gaat om individuele professionaliteit, ondersteund door institutionele cultuur en structuur. Dit houdt in dat het management van de organisaties waar zij werken de ruimte bieden voor interne discussie, maar tegelijkertijd onderzoekers in bescherming nemen tegen onheuse aanvallen en aantijgingen.

Naast die 'bevleugelende' stijl van leidinggeven kan het expliciet vooropstellen van het publieke belang daarbij goed werken.

Als het gaat om onderzoekersattitude en institutionele professionaliteit, verdient de betekenis van de 'W van Wetenschap' herwaardering: de waarde van de wetenschappelijke eed en de maatschappelijke verplichtingen die de doctorsbul schept, worden steeds meer gezien.

Dimensie 5: beeldvorming omgeven met harde waarborgen - een mogelijke toekomstige opgave voor het 'post-truth' tijdperk?

Dit is de dimensie die in een kennisdemocratie zoals de onze slechts in theorie bestaat: als het gaat om beeldvorming zijn er geen harde waarborgen die tot onafhankelijkheid in beeldvorming moeten leiden. Het door opiniemakers en samenleving als onafhankelijk en gezaghebbend gezien worden is iets dat zich niet laat afdwingen. Anders dan in bijvoorbeeld de voormalige Sovjet-Unie, Noord-Korea of China bestaat er in ons land gelukkig geen monopolie op kennis of wetenschap. Tegelijkertijd kan dit perspectief in de nabije toekomst in een ander daglicht komen te staan. Zo gaan er recentelijk, onder de druk van de almaar uitdijende hoeveelheid misinformatie die ons via de sociale media bereikt, steeds meer stemmen op voor duidelijkheid over de status van kennis. Saillant daarbij is de rol van landen die niet bekendstaan als kennisdemocratieën (bijvoorbeeld de desinformatie die vanuit Rusland via sociale media voorafgaand aan het Brexit-referendum werd verspreid).

Dimensie 6: beeldvorming versterkt door zachte maatregelen - het belang van presentatie en 'stoïcijnsheid'

Een zorgvuldige en tegelijkertijd overtuigende rapportage en presentatie van onderzoeksresultaten is van doorslaggevende betekenis in het vestigen en behouden van de reputatie van een onderzoeksinstituut of -commissie. De mate waarin rapportages, presentaties maar ook door onderzoekers of hun leidinggevende gegeven interviews erin slagen om duidelijke vraagstellingen te koppelen aan heldere conclusies is van groot belang voor de gepercipieerde onafhankelijkheid. De kracht van 'stoïcijnsheid' schuilt in het consequent terugbrengen van het onderzoek en de uitkomsten ervan naar waar het in de kern om gaat: is het beleid of het 


\section{Tabel 1 Zes dimensies voor het gericht werken aan onafhankelijk onderzoek}

\begin{tabular}{llll}
\hline $\begin{array}{l}\text { Zachte maatregelen: } \\
\text { professionaliteit }\end{array}$ & $\begin{array}{l}\text { Onderhouden van } \\
\text { relaties, responsiviteit } \\
\text { als grondhouding }\end{array}$ & $\begin{array}{l}\text { Wetenschappelijke } \\
\text { onderzoekersattitude, } \\
\text { 'bevleugelend' leider- } \\
\text { schap }\end{array}$ & $\begin{array}{l}\text { Vakkundige presenta- } \\
\text { tie, een zekere mate } \\
\text { van 'stoïcijnsheid' }\end{array}$ \\
$\begin{array}{l}\text { Harde waarborgen: } \\
\text { institutionalisering }\end{array}$ & $\begin{array}{l}\text { Juridische verankering, } \\
\text { financiële capaciteit }\end{array}$ & $\begin{array}{l}\text { Procedures, waar- } \\
\text { onder kwaliteitszorg }\end{array}$ & $\begin{array}{l}\text { Mogelijke opgave voor } \\
\text { 'post-truth' tijdperk: } \\
\text { tegengaan van misin- } \\
\text { formatie } \\
\text { Beeldvorming }\end{array}$ \\
\hline
\end{tabular}

bestuur erin geslaagd publieke belangen voldoende te dienen (vergelijk Wildavsky 1979, p. 231).

\section{Maatwerk in onafhankelijkheid: ook een zaak voor beleid en bestuur}

Het is goed dat de onafhankelijkheid van onderzoeksinstituten en de onderzoekers die daarbinnen werkzaam zijn, hoog op de agenda staat. Positief zijn ook de collectieve kennis en waarden die 'gestold' zijn in publicaties van KNAW, NWO, WRR en, recentelijk, de OVV. Maar zoals blijkt uit bovenstaande dimensies is er geen universele receptuur voor het borgen en versterken van de onafhankelijkheid van onderzoek: het is altijd maatwerk. Fundamenteel onderzoek is anders dan evaluatieonderzoek, onderzoek naar misstanden of ongevallen verschilt van onderzoek van toezichthouders. Voor vervolgonderzoek zou het daarom goed zijn om te kijken welke institutionele en professionele factoren in de verschillende functies en praktijksituaties bepalend zijn voor het afdoende borgen van onafhankelijkheid.

Het is in elk geval belangrijk om bij elk onderzoek de vraag te stellen hoe onderzoeker en opdrachtgever zich tot elkaar dienen te verhouden. Steeds weer, van situatie op situatie, van onderzoek op onderzoek, moet er worden gezocht naar een goede balans tussen betrokkenheid en afstand. Tussen de concrete vragen waar beleidsmakers en bestuurders 'gewoon' antwoorden op willen hebben en de wetenschappelijke mogelijkheden van onderzoekers. Voor het realiseren van een goede onderzoekspraktijk kan het in de ene situatie wenselijk zijn om onderzoekers letterlijk meer op afstand te plaatsen, terwijl het in het andere domein nodig kan zijn om hechte financiële banden te doorbreken.

Een relatief nieuw inzicht is dat dit niet alleen een taak is voor onderzoekers, maar net zo goed voor beleidsmakers en bestuurders. 'It takes two to tango', zoals het gezegde luidt, en dat geldt ook voor het zorgen voor de condities en het spel dat onafhankelijk onderzoek op een integere manier faciliteert. Het is wat ons betreft ongewenst om de scheiding tussen onderzoek en beleid op een dogmatische manier op te heffen: er bestaan goede bruggen om de spanning tussen de 
isolatie van de ivoren toren en het meedenken van onderzoekers die te dicht op hun beleidsterrein staan, goed te beheersen.

Waarheidsvinding is onmisbaar voor het vertrouwen dat mensen op de langere termijn in een democratie kunnen hebben. Onafhankelijkheid van onderzoek en evaluatie kunnen daarbij een cruciale rol hebben. Daarin schuilt, zoals de Onderzoeksraad voor Veiligheid vorig jaar in een mooie bundel concludeerde, bij uitstek de waarde van commissies en raden die een positie zonder ruggenspraak koppelen aan heldere oordelen en evenwichtige beeldvorming. Maar er lijkt ook veel te winnen bij zelfreflectie en eerlijkheid die van binnenuit komt. Het bestaan van onafhankelijke onderzoekers betekent immers niet dat je als ambtenaar of bestuurder niet ook zélf onderzoek kunt (laten) doen. Wie standaard nagaat hoe dingen beter kunnen (of hebben kunnen mislukken), bouwt aan een cultuur waar feiten en kennis ertoe doen. Oók als het om het voorkomen van rampspoed gaat.

Tot slot: de roeping om, binnen bestaande mogelijkheden, zo goed mogelijk onderzoek te doen geldt voor veel van de mensen die wij beroepsmatig kennen. Natuurlijk, de onafhankelijkheid die onderzoekers daarbij hebben, verschilt logischerwijs. In positie, in bevoegdheden, maar ook in de randvoorwaarden waarbinnen het onderzoek gedaan wordt. Volstrekt onafhankelijk is niemand. Dat kan ook helemaal niet in een land waarin samenwerken en aanpassen hoort bij succesvol functioneren. Maar wie vertrekt vanuit de vraag 'werkte onze aanpak voor de burger?' heeft altijd ijzersterke troeven in handen.

De onderzoeker die vervolgens op een transparante manier in kaart brengt wat er van goede bedoelingen terecht is gekomen en hoe verschillen verklaard kunnen worden, bewijst niet alleen zichzelf, maar iedereen die waarde hecht aan verantwoordelijkheid en veiligheid, een grote dienst.

\section{Literatuur}

Koninklijke Nederlandse Akademie van Wetenschappen (KNAW). (2005). Over de omgang tussen wetenschappelijk onderzoekers en hun opdrachtgevers. Amsterdam: KNAW.

Nederlandse Organisatie voor Wetenschappelijk Onderzoek (NWO). (2018). Nederlandse gedragscode wetenschappelijke integriteit. Den Haag: NWO.

Onderzoeksraad voor Veiligheid (OVV). (2018). Onafhankelijk onderzoek in het publiek belang. Den Haag: Onderzoeksraad voor Veiligheid.

Stichting Maatschappij en Veiligheid (SMV). (2018). Kaderwet Onafhankelijk OnderzoekOm lering te kunnen trekken uit gebeurtenissen. Den Haag: SMV.

Wetenschappelijke Raad voor het Regeringsbeleid (WRR). (2013). Toezien op publieke belangen. Den Haag: WRR.

Wildavsky, A. (1979). Speaking truth to power - The art and craft of policy analysis. New Brunswick: Transaction Books. 